Review Article

\title{
Intracellular Regulation of Matrix Metalloproteinase-2 Activity: New Strategies in Treatment and Protection of Heart Subjected to Oxidative Stress
}

\author{
Grzegorz Sawicki'1,2 \\ ${ }^{1}$ Department of Pharmacology, College of Medicine, University of Saskatchewan, 107 Wiggins Road, Saskatoon, SK, Canada S7N 5E5 \\ ${ }^{2}$ Department of Clinical Chemistry, Medical University of Wroclaw, Wrovasc Integrated Cardiovascular Centre, \\ 50-556 Wroclaw, Poland
}

Correspondence should be addressed to Grzegorz Sawicki; greg.sawicki@usask.ca

Received 10 November 2013; Accepted 3 December 2013

Academic Editors: C. F. Sier and L. Xi

Copyright (c) 2013 Grzegorz Sawicki. This is an open access article distributed under the Creative Commons Attribution License, which permits unrestricted use, distribution, and reproduction in any medium, provided the original work is properly cited.

Much is known regarding cardiac energy metabolism in ischemia/reperfusion (I/R) injury. Under aerobic conditions, the heart prefers to metabolize fatty acids, which contribute to $60-80 \%$ of the required ATP. During ischemia, anaerobic glycolysis increases and becomes an important source of ATP for preservation of ion gradients. With reperfusion, fatty acid oxidation quickly recovers and again predominates as the major source of mitochondrial oxidative metabolism. Although a number of molecular mechanisms have been implicated in the development of I/R injury, their relative contributions remain to be determined. One such mechanism involves the proteolytic degradation of contractile proteins, such as troponin I (TnI), myosin heavy chain, titin, and the myosin light chains (MLC1 and MLC2) by matrix metalloproteinase-2 (MMP-2). However, very little is known about intracellular regulation of MMP-2 activity under physiological and pathological conditions. Greater understanding of the mechanisms that govern MMP-2 activity may lead to the development of new therapeutic strategies aimed at preservation of the contractile function of the heart subjected to myocardial infarction (MI) or I/R. This review discusses the intracellular mechanisms controlling MMP-2 activity and highlights a new intracellular therapeutic direction for the prevention and treatment of heart injury.

\section{MMPs General Characteristics}

Matrix metalloproteinases (MMPs) are proteolytic enzymes, which play significant roles in a range of physiological processes including morphogenesis, cartilage and bone repair, wound healing, cell migration, and angiogenesis. They are best known for their role in degradation of extracellular proteins and remodeling of the extracellular matrix. MMPs belong to a family of more than 25 enzymes that are not only structurally related but are also similar in substrate specificity [1-4]. Of these, the best known enzyme is matrix metalloproteinase-2 (MMP-2 or gelatinase A) and matrix metalloproteinase-9 (MMP-9 or gelatinase B). MMP-2, a constitutive enzyme, is found in almost all cell types and it degrades denatured collagen (gelatin) and collagen type IV (a component of the basement membrane) as well as other extracellular matrix proteins [5-7]. MMP-9 is a cytokine inducible MMP which is most commonly located in leukocytes [8-10]. Enzymes of this family possess a signal peptide, amino-terminal propeptide, a catalytic $\mathrm{Zn}$ binding site, and carboxy terminus domains [11-13].

Enhanced activity of MMPs, such as MMP-2 and MMP-9, is implicated in a variety of cardiovascular pathological states, including atherosclerosis, restenosis, ischemic heart disease, and heart failure $[14,15]$. But attention was always given to the effects of MMP activities in tissues on a long-term scale (days or weeks) and to the associated changes in the extracellular matrix (protein degradation and remodeling of extracellular matrix).

\section{Regulation of MMP Activity}

Similar to other proteolytic enzymes, all MMP activity is regulated at several levels such as transcription, regulation of mRNA half-life, secretion, intra- or extracellular localization, 
enzyme activation, and inhibition by specific and nonspecific proteinase inhibitors [16-25]. Described below are the three basic mechanisms: activation by proteolytic removal of propeptide, regulation of proteolytic activity by inhibitors, and chemical modification of enzyme molecule.

2.1. Regulation by Proteolytic Cleavage of Proenzyme. MMPs are expressed as latent enzymes. They can be activated by proteolytic cleavage of the $\mathrm{N}$-terminal propeptide by a membrane-type MMP (MT-MMP) [18, 20, 22-24]. In this mode, the so-called "pro-MMP-2" $(72 \mathrm{kDa})$ is activated by removing $\mathrm{N}$-terminal part of proenzyme by action of a membrane-type MMP (MT-MMP) [18, 22, 24, 26] to its enzymatically active form, which is shorter by approximately $10 \mathrm{kDa}(64 \mathrm{kDa})$. The proteolytic removal of the propeptide region perturbs the binding of a cysteine thiol residue with the active zinc ion $\left(\mathrm{Zn}^{+2}\right)$ site. This process is instrumental for the expression of proteolytic activity [17, 27-29].

2.2. Regulation by Proteinase Inhibitors. Similar to other enzymes, MMPs are regulated by naturally occurring inhibitors called tissue inhibitors of metalloproteinases (TIMPs) $[13,15,30,31]$. To date, 4 TIMPs have been described, TIMP-1, TIMP-2, TIMP-3, and TIMP-4. TIMPs are tight binding proteins and relatively small molecules, between 20 and $30 \mathrm{kDa}$. It is worth mentioning that peroxynitrite $\left(\mathrm{ONOO}^{-}\right)$, a very potent reactive oxygen species, may also alter the structural and binding characteristics of TIMPs, resulting in their dissociation or lower affinity to MMPs [32]. The modification of TIMP may also lower affinity to pro-MMPs, resulting in the activation or impaired regulation of MMP activity [32].

In addition to natural protein inhibitors of MMPs, a broad range of synthetic compounds with anti-MMP activity are described. Synthetic inhibitors such as o-phenanthroline (Phen), hydroxamates, and the tetracycline-class of antibiotics, of which doxycycline (Doxy) is the most potent [3337], share the common characteristic of chelating $\mathrm{Zn}^{2+}$. In studies which involve use of MMP inhibitors, Doxy is the reagent of choice. The effect of Doxy used as an MMP inhibitor in experimental and clinical studies is reviewed extensively by Castro and Tanus-Santos [38]. Unfortunately, despite the fact that many researchers claim these inhibitors as selective/specific inhibitors of MMPs, these compounds always affect the action of other proteolytic enzymes in addition to inhibiting MMPs [39-41].

\subsection{Regulation by Posttranslational Modification of Enzyme} Molecule. Regulation of metabolic enzymes or proteins involved in signal transduction by posttranslational modifications such as acetylation, nitrosylation, or phosphorylation in in vivo conditions is well documented [42-47]. However, almost nothing is known about chemical posttranslational modifications of MMPs in vivo and their effect on MMP activity. However, it has been shown under in vitro conditions that low concentrations of reactive oxygen species (ROS) increased MMP activity $[48,49]$, while higher concentrations decreased MMP-2 activity [50]. The role of ROS in oxidative stress pertaining heart injury will be discussed later.

In addition to the proteolytical cleavage, the disruption of the Cys- $\mathrm{Zn}^{2+}$ bond can be also induced by oxidizing agents like peroxynitrite $\left(\mathrm{ONOO}^{-}\right)$. Maeda's group $[48,49]$ showed that low concentrations of $\mathrm{ONOO}^{-}$activate pro-MMP without removal of the autoinhibitory propeptide domain. In fact, in the presence of normal intracellular levels of glutathione, $\mathrm{ONOO}^{-}$causes the S-glutathiolation of a sequence within this autoinhibitory domain of MMPs [51]. Thus $\mathrm{ONOO}^{-}$ may alter the conformation of enzyme molecules, leading to their inactivation and resulting in increased MMP activity $[32,52]$. The activation of MMP-2 in the presence of $\mathrm{ONOO}^{-}$and glutathione $(\mathrm{GSH})$ together is greater than with $\mathrm{ONOO}^{-}$alone [51]. Recently we showed that in addition to $\mathrm{ONOO}^{-}$dependent modifications, phosphorylation of MMP-2 decreased its in vitro activity [53]. Also it was shown that phosphorylation of a proform of MMP-2 determines the enzyme conformation and response to $\mathrm{ONOO}^{-}$[54]. The intracellular activation of MMP-2 by ROS and its possible consequences in heart diseases are reviewed in [55].

Thus, there is a natural mistake in MMP nomenclature, as the term "pro-MMP" is generally used to describe the molecule with higher molecular weight as a "latent" enzyme, assuming that only the molecule with lower molecular weight is active.

As mentioned above, all our knowledge about the role of posttranslational modifications on MMP activity originated from in vitro studies. Our most recent studies, using a model of $\mathrm{I} / \mathrm{R}$ injury, showed that the phosphorylation of MMP-2 molecule is important for its activity [53] and that inhibition of dephosphorylation of MMP-2 protects heart from contractile dysfunction caused by I/R [56].

\section{Discovery of the Novel Action of MMP-2}

Fifteen years ago, work of Marek Radomski's group from Edmonton, Canada (currently Dublin, Ireland), on the mechanisms of the regulation of platelet function by nitric oxide (NO) showed a novel pathway of platelet aggregation mediated by MMP-2 [57-60]. He and his coworkers, for the first time, characterized the ultrastructural localization and cellular translocation of MMP-2 in the stimulated human platelet [59]. This was the first piece of evidence showing that MMP-2 acts not only in the extracellular matrix but also at the cellular level, with a time frame of action of minutes rather than hours or days. Soon after that, the mechanism of platelet dysfunction encountered during the use of extracorporeal membrane oxygenation (ECMO) was also investigated [57]. This study showed that metalloproteinase inhibitors might provide a means to intervene in the state of dysregulated platelet aggregation seen in ECMO, ultimately, leading to preservation of normal platelet homeostasis and minimization of the deleterious consequences of this lifesaving therapy. This study provided the foundation for the development of a new approach in the study of MMP biology.

Shortly after these findings, several new actions of MMP2 , unrelated to the extracellular matrix, were revealed. These 
actions include the degradation of big endothelin [61], calcitonin gene-related peptide [62], and monocyte chemoattractant protein-3 [63]. MMP-2 was also shown to mediate neurotoxicity in HIV-infected macrophages by cleavage of the chemokine stromal cell-derived factor-1 [64].

In 1999 a sarcomeric association of MMP-2 was found in hearts of patients with dilated cardiomyopathy $[65,66]$. Soon after that, it was shown that the action of MMP-2 included not only the intracellular degradation of troponin I (TnI) [67] and myosin light chain 1 (MLC1) [68], but also the degradation of poly (ADP-ribose) polymerase in the nucleus [69]. While working on apoptosis in cardiomyocytes, Menon and colleagues also observed an intracellular action of MMP-2 [70]. In addition, a new intracellular function of MMP-2 as an active negative regulator of mitochondrial function during superimposed oxidative stress was reported [71]. Novel intracellular functions were also found for MMP-1 and MMP- 3 as mediators of apoptosis $[72,73]$ and for MMP-9 as a mitochondrial enzyme which, when activated, decreases myocyte contractility in hyperhomocysteinemia [74]. Indeed, several reports now indicate that MMP-2 does not solely degrade proteins of the extracellular matrix (reviewed in [75-77]). The most recent studies, which use cardiomyocytes subjected to oxidative stress, revealed the presence of a truncated isoform of MMP-2 in intracellular space, and this form of MMP-2 is responsible for initiation of innate immunity [78].

\section{MMP-2 in Acute Heart Injury}

The detrimental roles of matrix metalloproteinases in cardiovascular disease states such as atherosclerosis and heart injury have been postulated [12, 79, 80]. Richard Schulz group from Edmonton, Canada, studied the role of MMP2 with respect to oxidative stress in the heart triggered by ischemia/reperfusion (I/R) injury. He has shown that MMP2 contributes to acute cardiac dysfunction and its inhibitors protect the heart from this injury [81]. Subsequently, he has shown that an intracellular contractile machinery regulatory protein, troponin I (TnI), is degraded by MMP-2 in I/R injury [67]. This was the first report showing intracellular function of an "extracellular enzyme." Furthermore, an intracellular imbalance between an endogenous tissue inhibitor of metalloproteinases-4 (TIMP-4) and MMP-2 was shown in I/R injury [82]. These important discoveries provided the base for a new paradigm pertaining to the site of MMP-2 activity. Also, these discoveries started the momentum for the development of novel pharmacological strategy in the treatment of I/R injury.

It was suspected that $\mathrm{TnI}$ is not the only intracellular protein degraded by MMP-2 in I/R heart injury. In order to address this, a combined pharmacological and functional proteomics approach was used to analyze protein changes in $\mathrm{I} / \mathrm{R}$ hearts. In this experimental setting we discovered that myosin light chain 1 (MLC1) is another target of MMP-2 [68]. Additionally, the most recent study from our laboratory has shown that MMP-2 is involved in the damage of endothelial integrity in $\mathrm{I} / \mathrm{R}$ hearts [83]. This damage is associated with increased protein release into coronary effluent; however, the molecular mechanism of this phenomenon still has yet to be elucidated. In 2010, myocardial MLC2 [84] and titin [85] were identified as new MMP-2 substrates in oxidative stress.

The novel aspects of MMP-2's action in heart injury have been reviewed by Schulz [86], the role of MMPs in cardiac diseases has been reviewed by Spinale [87], and the intracellular actions of MMPs have been reviewed by Hockenbery [77].

\section{Oxidative Stress}

The following is a brief introduction in order to better understand the role of oxidative stress and, more specifically, the role of reactive oxygen species (ROS) in heart injury.

Oxidative stress is a common cause of heart injury and reflects an imbalance between ROS and ability of an organism to remove or inactivate the reactive entities or to repair the resulting tissue damage. ROS are toxic molecules formed during a variety of normal and pathological biochemical reactions. They are highly reactive and unstable. Furthermore, their reactions may lead to DNA damage, mitochondrial malfunction, cell membrane damage, and eventually cell death, a phenomenon referred to as "oxidative stress." Oxidative stress results from an imbalance between the formation and the neutralization of prooxidants. Examples of ROS include hydrogen peroxide $\left(\mathrm{H}_{2} \mathrm{O}_{2}\right)$, hydroxyl radical $\left({ }^{\circ} \mathrm{OH}\right)$, nitric oxide (NO), singlet oxygen $\left({ }^{1} \mathrm{O}_{2}\right)$, superoxide anion $\left(\mathrm{O}_{2}{ }^{-}\right)$, peroxyl radical $\left(\mathrm{ROO}^{\circ}\right)$, and peroxynitrite $\left(\mathrm{ONOO}^{-}\right)$. $\mathrm{ONOO}^{-}$is a very potent entity, being $\sim 1000 \times$ stronger as an oxidizing agent than $\mathrm{H}_{2} \mathrm{O}_{2}$. Markers of $\mathrm{ONOO}^{-}$formation (such as nitrotyrosines or isoprostanes) can be found in many disease states including, but not limited to, brain injury [88-91], heart [92-94], lung [95, 96], liver disease $[97,98]$, preeclampsia $[99,100]$, and inflammation $[96,101-$ 104], among others.

All cell types are capable of producing ROS, and evidence suggests that ROS produced by cardiovascular cells play important roles in the development and progression of heart injury and disease. Recent experimental studies suggest causational roles for increased ROS in the development of contractile dysfunction following myocardial infarction (MI) and pressure overload [105]. However, the precise contribution of ROS in cardiovascular pathologies remains unknown. The present review addresses this issue, specifically the action of $\mathrm{ONOO}^{-}$on the molecular mechanisms of heart function. $\mathrm{ONOO}^{-}$results from an extremely rapid reaction between ${ }^{\circ} \mathrm{NO}$ and ${ }^{\circ} \mathrm{O}_{2}{ }^{-}$. It is then protonated to form the chemically unstable intermediate, peroxynitrous acid $(\mathrm{ONOOH})$, which rapidly decomposes to form highly reactive oxidant species including ${ }^{\circ} \mathrm{OH}$, nitrogen dioxide radicals $\left({ }^{\circ} \mathrm{NO}_{2}\right)$, and the nitronium cation $\left(\mathrm{NO}_{2}^{+}\right)$[106].

The coupling between cardiac energy usage and contractility makes the heart a unique and excellent organ model for investigating the mechanisms of oxidative stress (e.g., triggered by ischemia/reperfusion (I/R) injury) and for determining the efficacy of new therapeutic agents. Despite the variations in the anatomy and physiology of different 
organs, the basic molecular and cellular mechanisms of all I/R injury and protection are essentially similar throughout the body.

\section{Pathophysiological Roles of Reactive Oxygen Species in the Heart}

The general role of reactive oxygen species (ROS) in I/R injury has been extensively researched, with many studies showing a burst in ROS generation at the start of reperfusion (reviewed in [107]). However, increased ROS formation during ischemia remained unverified until our most recent work showed an increased production of $\mathrm{ONOO}^{-}$during ischemia in isolated myocytes [108].

Whether or not NO plays a protective or detrimental role in I/R injury has been a controversial issue that requires an understanding of the biology of $\mathrm{NO}, \mathrm{O}_{2}{ }^{-}$, and $\mathrm{ONOO}^{-}$ to resolve. The critical physiological balance between cellular concentrations of $\mathrm{NO}, \mathrm{O}_{2}{ }^{-}$, and superoxide dismutase favours NO production, but under pathological conditions such as $\mathrm{I} / \mathrm{R}$ or $\mathrm{H}-\mathrm{R}, \mathrm{ONOO}^{-}$production is increased (reviewed in [109]). Within the normal heart, NO is synthesized by cardiac myocytes, endocardial endothelial cells, and vascular endothelial cells using NO synthase (NOS), known as endothelial NOS (eNOS) [110]. The production of $\mathrm{NO}$ is important for maintaining a variety of physiological functions within the heart such as setting coronary vasodilator tone, modulating myocardial contractile function, and providing an antioxidant environment [111]. The role of NO in delayed pharmacologically induced preconditioning was revived by $\mathrm{Xi}$ and Kukreja [112]. The cardioprotective effect of $\mathrm{ONOO}^{-}$was observed for the first time by Lefer's group [113]. He and his colleagues showed that infusion of low concentrations of $\mathrm{ONOO}^{-}(2 \mu \mathrm{M})$ protected heart from myocardial ischemia and reperfusion injury. Also, it has been shown that oxidant species, such as ${ }^{\circ} \mathrm{HO}$ and $\mathrm{ONOO}^{-}$, trigger late preconditioning against myocardial stunning [114]. Very recently, Liaudet's group showed that $\mathrm{ONOO}^{-}$is a key mediator for induction of cardioprotective mechanism during postconditioning [115]. On the other hand, Schulz et al. have also shown a cytotoxic effect of NO on heart tissue [116], and despite the evidence that $\mathrm{ONOO}^{-}$contributes to $\mathrm{I} / \mathrm{R}$ injury, its precise role remains unsolved [117-120]. A search for critical targets of $\mathrm{ONOO}^{-}$or $\mathrm{NO}$ is a new approach to minimizing or preventing injury to the heart during oxidative stress. Work done by myself and others [48-50, 121], showing that $\mathrm{ONOO}^{-}$activates matrix metalloproteinases (MMPs), and that MMPs have novel intracellular functions $[57,58,60-65,69]$, prompted the proposed investigation.

It is significant to point out that ROS act on many targets, including kinases. For example, mitochondrial ROS initiate the phosphorylation of p38 MAP kinase [122], activate additional MAPK pathways [123] such as protein kinase B [124] and Src tyrosine kinases [125], and can induce nitration of PKCepsilon by NO facilitating its interaction with RACK2 for translocation and activation [126].

This review will help to clarify the role of ROS, including $\mathrm{ONOO}^{-}$and phosphorylation, on potential MMP substrates and explain the mechanism of intracellular regulation of MMP-2 in physiology in hopes of better understanding its regulation in heart injury triggered by oxidative stress.

\section{Intracellular Regulation of MMP-2 Activity}

In general, MMP production and activity in vivo are strictly regulated. What is new, and to my knowledge, not yet broadly known and investigated in relation to oxidative stress, is the regulation of proteolytic activity of proteinases (not only MMPs) by the posttranslational modifications that render normally proteolysis-resistant proteins susceptible to these enzymes. The discovery of new sarcomeric substrates for MMP-2 in injured heart, such as TnI, titin, MLC1, and MLC2, raised questions concerning the intracellular regulation of MMP-2.

Most studies in this area were done with the use of MLC1 and MLC2. MLCs were used to address these questions because they already were known to be key proteins affected by oxidative stress $[68,84]$, and their chemical properties favoured them over other contractile proteins. The other contractile proteins are very difficult to study when techniques involved in studying protein electromobility are used. TnI is a very basic protein $(\mathrm{pI} \sim 10.5)$ and therefore is very difficult to use in studies involving 2-dimensional electrophoresis. Titin is a huge protein $(\sim 3.5 \mathrm{MDa})$ and is also very difficult to study with techniques involving electrophoretic separation.

Most recently, we have shown the involvement of $\mathrm{ONOO}^{-}$in nitration and nitrosylation of MLC1 and MLC2 from hearts subjected to $\mathrm{H}-\mathrm{R}$, and that these modifications increased their degradation by MMP-2 [84, 127]. These observations were confirmed in another model of oxidative stress, isolated cardiomyocytes subjected to hypoxia-reoxygenation (H-R), in which the $\mathrm{ONOO}^{-}$scavenger FeTPPS protected against H-R-induced contractile dysfunction [108]. We have shown that in vitro, phosphorylation and nitration of MLC1 increase its degradation by MMP-2 [108]. Also, our most recent data from animal model of I/R injury [128] and H-R with use isolated cardiomyocytes [108] show phosphorylation, nitration, and nitrosylation of MLC1 from I/R hearts. Phosphorylation and nitration of the crucial residues were found only in the MLC1 from I/R hearts; therefore, these modifications may be responsible for sensitizing MLC1 to degradation by MMP-2 and thus may play an important role in regulating the intracellular action of MMP-2 during I/R injury. Collectively, our data, together with other reports [129-132], suggest that studying MLC posttranslational modifications could provide new information that will lead to the discovery of the missing link in the mechanism of intracellular regulation of MMP-2 activity. These discoveries would provide support for a new paradigm pertaining to the regulation of MMP-2 activity and to the site of MMP2 action and the impetus for the development of a novel pharmacological strategy in the treatment of oxidative stress (I/R or H-R) injury.

To summarize, the detrimental role of ROS and increased MMP-2 activity on heart function is documented. However, the myocardial protein targets for ROS are still not fully 
identified and the molecular consequences of ROS action remain unknown. This is why my general hypothesis is that the oxidative stress triggers posttranslational modifications of contractile proteins and most likely other proteins as well. Following these changes, the proteins become substrate for MMPs. Oxidative stress also increases MMP activity, which was evidenced by us and others [133-136], and this increased activity contributes to the impairment of myocardial contractile function by degradation of previously proteolysisresistant contractile proteins. Thus, the pharmacological inhibition of contractile protein modification, together with the inhibition of MMP activity, should provide adequate protection to the heart from MI, I/R, or generally speaking, from injury triggered by oxidative stress.

\section{Modifications of MLCs Triggered by Oxidative Stress in Isolated Rat Heart}

Very little is known about the regulation of MMP-2 activity in the myocardium. While we have already shown that the balance between MMP-2 and TIMP-4 is disrupted in the heart subjected to I/R injury [82], there must also be other intracellular mechanisms of MMP-2 regulation.

Using our heart contractility recovery criteria [137] and 2-dimensional electrophoresis, we found the level of the truncated form of MLC1 in I/R hearts to be approximately double that in aerobic controls [128]. This increased level of the truncated form of MLC1 was negatively correlated with recovery and positively correlated with increased MMP-2 activity, which was correlated with the duration of ischemia [137]. However, while immunoblotting analysis showed a $40 \%$ decrease in total MLC1 in the I/R group (data not published), the level of intact MLC1 ( $>95 \%$ content of total MLC1), as measured by 2-dimensional electrophoresis, remained unchanged (data not published). This discrepancy could be explained by decreased immunoreactivity of MLC1 caused by posttranslational modifications inside an epitope of MLC1, triggered by $\mathrm{I} / \mathrm{R}$ injury. This phenomenon is not unique; similar discrepancies have been reported in actin levels in an in vivo model of MI [138] and in an islet amyloid peptide epitope from diabetic patients [139].

Our mass spectrometry analysis showed qualitative and quantitative differences between MLC1 from control and I/R hearts (data not published). Data from the analysis of peptide mass fingerprints (PMF) showed similar amounts of modified and nonmodified peptides of intact MLC1 isolated from aerobic and I/R hearts, but twice as many peptides with posttranslational modifications in the truncated form of MLC1 from I/R hearts. In summary, oxidative stress triggered by I/R caused extensive posttranslational modifications of the MLC1 molecule. We also have substantial preliminary evidence demonstrating that MLC1 from I/R is phosphorylated [128], nitrated, and nitrosylated [108]. In vitro experiments showed enhanced degradation of phosphorylated MLCl and that phosphorylated MLC1 had a higher affinity for MMP2 than the nonphosphorylated form [128]. Similarly, nitration/nitrosylation of $\mathrm{MLCl}$ caused by $\mathrm{ONOO}^{-}$treatment increased MLC1 degradation, with a correlation between the degree of degradation and $\mathrm{ONOO}^{-}$concentration [108]. While nitration of tyrosine is considered as a key target of $\mathrm{ONOO}^{-}$action, phenylalanine nitration by $\mathrm{ONOO}^{-}$is also documented [140-142] although very little is presently known about it.

\section{Identification of the Chemical Modifications of MLCs and MMP-2 Triggered by Oxidative Stress and Their Role in Isolated Cardiac Myocytes}

Our work and that of others have shown that (a) oxidative stress injury caused by I/R [67, 68, 81, 82], infusion of $\mathrm{ONOO}^{-}$[143] or cytokines [144] into the myocardium, or $\mathrm{H}$ $\mathrm{R}$ [145] increases the activity of MMP-2; (b) this activity is positively correlated with the degree of injury $[79,137]$; and (c) MMP-2 is colocalized within the sarcomeres of cardiac myocytes with TnI, titin, MLC1, and MLC2 [67, 68, 84, 85]. All of these observations, made in intact, isolated hearts and in the rapid time course of the injury process (minutes), appear to be independent of changes in collagen content $[82,144]$. For the reason that the heart is a very complex organ, it is important to identify the precise location of MMP2 action. To confirm that our isolated heart model findings reflect the intracellular actions of MMP-2, use of isolated myocytes subjected to $\mathrm{H}-\mathrm{R}$ is fully justified. This biological model indicates whether the intracellular action of ROS in a single cell directly modulates sarcomeric MLC levels and/or triggers chemical modifications and if these modifications are associated with intracellular MMP-2 action on sarcomeric MLC1 and MLC2. Modifications of intracellular MMP-2 and changes in its activity can be investigated as well.

Using isolated cardiac myocytes, it has been shown that $\mathrm{ONOO}^{-}$caused a concentration-dependent reduction of myocyte contractility. This increased MMP-2 activity and the infusion of MMP inhibitors, doxycycline or PD 166793, attenuated the reduced contraction induced by $\mathrm{ONOO}^{-}$ [146]. This was the first demonstration that inhibition of MMPs could protect the isolated cardiac myocyte from $\mathrm{ONOO}^{-}$-induced contractile failure, and that MMPs cause this via a mechanism of action unrelated to proteolysis of extracellular matrix proteins. In our most recent work [108] using isolated cardiomyocytes subjected to 60 minutes of simulated ischemia, $\mathrm{ONOO}^{-}$-modified MLC1 increased degradation of MLC1 by MMP-2, and $\mathrm{ONOO}^{-}$scavengers protected cardiomyocytes from contractile dysfunction triggered by oxidative stress.

My group showed that MLC1 from isolated myocytes subjected to simulated ischemia is S-nitrosylated and nitrated. These data show that the posttranslational modifications of MLC1 are most associated with nitration of tyrosine 190 and tyrosine 78 and S-nitrosylation of cysteine 81 . For the reason that the observed posttranslational modifications in MLC1 from myocytes subjected to simulated ischemia are similar, but not identical to those observed in MLC1 isolated from I/R hearts, use of the chemically induced H-R model [147-149] is a better choice than the simulated ischemia model. 


\section{Protection of the Heart from H-R-Induced Contractile Dysfunction in a Model of Neonatal Asphyxia}

It is important to understand whether the observations involving modifications of MLCs in I/R and H-R injury are a common phenomenon related to the nature of oxidative stress. To address this question a piglet model of neonatal asphyxia (H-R model) is a good choice. Neonatal asphyxia is a clinical condition that affects millions of newborns worldwide annually. Using a piglet model of neonatal asphyxia, decreased levels of MLC1 and MLC2 found were in the heart of animals subjected to $\mathrm{H}-\mathrm{R}$, which were associated with an increased level of MMP-2 [84, 127]. In contrast to I/R studies, only $\mathrm{ONOO}^{-}$-dependent modifications of MLCs were observed in this model of H-R $[84,127]$.

\section{Final Remarks and Possible Clinical Implications}

Phosphorylation of MLC1 has been previously described $[129,150]$. While speculation involving its physiological role is still related to the modulation of contractile force, the pathological implications of MLC1 phosphorylation are not understood. Degradation of MLC1 during oxidative stress and I/R injury has been postulated and established $[68,108$, $127,151]$. Nonetheless, the mechanism by which proteolytic degradation of contractile proteins occurs remains to be established. Phosphorylation of MLC1 has been shown in physiological conditions [151] as well as in chemically induced preconditioning [129]. However, the mechanism of MLC1 phosphorylation and its role in cardiac function are far from being understood.

In this review I focused on the intracellular mechanism by which MMP-2 acts on MLCs, but mostly on oxidative stress-mediated intracellular modification of MLC1 through phosphorylation, nitration or nitrosylation. This modification results in an increased degradation of MLC1 and MLC2 by the proteolytic enzyme MMP-2 that results in decreased mechanical function of the injured heart. Furthermore, I discussed the possible prevention of both the degradation of MLC1 and reduction in contractile function of the I/R heart by both inhibition of MLC phosphorylation and MMP2 activity. I have also discussed the novel possible pharmacological approach when inhibitors of MLC modifications are infused to the I/R heart simultaneously with inhibitors of MMP-2 activity. In such a therapeutic scenario a synergistic protective effect is observed in regard to the contractility of injured hearts.

The concept of reperfusion injury is recognized as a clinical phenomenon that may result in microvascular damage or myocardial stunning. The final consequence of this event is left ventricular systolic dysfunction leading to increased morbidity and mortality. The typical clinical case of reperfusion injury occurs in acute $\mathrm{MI}$ in which an occlusion of a coronary artery is followed by reopening of the artery. Another case is coronary artery bypass graft surgery (CABG).

Currently, the most important goal of pharmacological prevention and therapy in the course of heart disease,
Pincluding MI, is to improve the oxygen supply/demand ratio for the heart [152-154]. For the prevention and treatment of MI, current clinical practice involves a multidrug regimen targeting restoration of normal coronary blood flow and/or decrease of myocardial oxygen consumption. Agents which either clinically or experimentally reduce the extent of myocardial injury when administrated just prior to reperfusion involve cell membrane receptor agonist adenosine, angiotensin-converting enzyme inhibitors, opioids and erythropoietin or the mixed cell membrane, and intracellular agonists [155]. Currently, more than $90 \%$ of patients on hospital arrival with suspicion of acute MI are given aspirin and/or a $\beta$-blocker [156]. Further treatment is based on analysis of factors including beginning and duration of symptoms, patient history, electrocardiogram, and physical examination of the patient.

Because there is no agent universally accepted to prevent or treat reperfusion injury, new directions in pharmacological treatment of the injured heart or protection from MI are needed and are under investigation. Therefore, it is important to unravel mechanisms involved in heart injury and to develop new pharmacological strategies for the treatment of MI.

On the basis of the information provided here I am almost positive that in addition to the existing approaches in clinical practice for protection and treatment of heart injury from oxidative stress, MMP inhibitors and inhibitors of modifications, like nitration, hydroxylation, S-nitrosylation, and phosphorylation, hold great potential as novel strategies to reduce the impact of ischemic heart disease. Recent studies by Ceriasano's group showed that doxycycline (inhibitor of MMPs) therapy in patients with acute MI and left ventricular dysfunction prevents the progression of adverse remodeling myocardium [157]. The studies presented in this review show that testing potential therapeutic agents for synergism in reperfusion protection should lead to the development of a "drug cocktail" or a "super pill" to protect the hearts of human patients from I/R injury. The concept of protecting I/R hearts using the synergistic action of drugs inhibiting modifications of contractile proteins together with inhibition of MMP-2 activity is currently under investigation in my lab and has been reviewed $[158,159]$.

Because the basic molecular and cellular mechanisms of all I/R injury and protection are essentially similar throughout the body, this concept is important to all pathologies involving $\mathrm{I} / \mathrm{R}$, including transplantation or reattachment of limbs. Finally, this novel approach will provide evidence to support the development of new directions in the study of the mechanisms of heart failure.

\section{Acknowledgments}

This review paper was funded in part by grants from Canadian Institutes of Health Research (CIHR), the Saskatchewan Health Research Foundation (SHRF), Heart and Stroke Foundation of Canada (HSFC), and National Center of Science in Poland by Grant no. DEC-2012/06/M/NZ3/00158. The author is a scholar supported by CIHR and SHRF. 


\section{References}

[1] N. M. Hooper, "Families of zinc metalloproteases," FEBS Letters, vol. 354, no. 1, pp. 1-6, 1994.

[2] M. M. Handsley and D. R. Edwards, "Metalloproteinases and their inhibitors in tumor angiogenesis," International Journal of Cancer, vol. 115, no. 6, pp. 849-860, 2005.

[3] M. H. Tayebjee, G. Y. H. Lip, and R. J. MacFadyen, "Matrix metalloproteinases in coronary artery disease: clinical and therapeutic implications and pathological significance," Current Medicinal Chemistry, vol. 12, no. 8, pp. 917-925, 2005.

[4] H. Nagase, R. Visse, and G. Murphy, "Structure and function of matrix metalloproteinases and TIMPs," Cardiovascular Research, vol. 69, no. 3, pp. 562-573, 2006.

[5] H. Birkedal-Hansen, W. G. I. Moore, M. K. Bodden et al., "Matrix metalloproteinases: a review," Critical Reviews in Oral Biology and Medicine, vol. 4, no. 2, pp. 197-250, 1993.

[6] S. Löffek, O. Schilling, and C.-W. Franzke, "Series "matrix metalloproteinases in lung health and disease": biological role of matrix metalloproteinases: a critical balance," European Respiratory Journal, vol. 38, no. 1, pp. 191-208, 2011.

[7] C. J. Morrison, G. S. Butler, D. Rodríguez, and C. M. Overall, "Matrix metalloproteinase proteomics: substrates, targets, and therapy," Current Opinion in Cell Biology, vol. 5, pp. 645-653, 2009.

[8] W. E. Horton Jr., I. Udo, P. Precht, R. Balakir, and K. Hasty, "Cytokine inducible matrix metalloproteinase expression in immortalized rat chondrocytes is independent of nitric oxide stimulation," In Vitro Cellular and Developmental BiologyAnimal, vol. 34, no. 5, pp. 378-388, 1998.

[9] M. Iwata, M. Pillai, A. Ramakrishnan et al., "Reduced expression of inducible gelatinase $\mathrm{B} /$ matrix metalloproteinase-9 in monocytes from patients with myelodysplastic syndrome: correlation of inducible levels with the percentage of cytogenetically marked cells and with marrow cellularity," Blood, vol. 109, no. 1, pp. 85-92, 2007.

[10] J. Westermarck and V.-M. Kähäri, "Regulation of matrix metalloproteinase expression in tumor invasion," FASEB Journal, vol. 13, no. 8, pp. 781-792, 1999.

[11] H. Nagase, R. Visse, and G. Murphy, "Structure and function of matrix metalloproteinases and TIMPs," Cardiovascular Research, vol. 69, no. 3, pp. 562-573, 2006.

[12] C. B. Jones, D. C. Sane, and D. M. Herrington, "Matrix metalloproteinases: a review of their structure and role in acute coronary syndrome," Cardiovascular Research, vol. 59, no. 4, pp. 812-823, 2003.

[13] R. Visse and H. Nagase, "Matrix metalloproteinases and tissue inhibitors of metalloproteinases: structure, function, and biochemistry," Circulation Research, vol. 92, no. 8, pp. 827-839, 2003.

[14] E. E. J. M. Creemers, J. P. M. Cleutjens, J. F. M. Smits, and M. J. A. P. Daemen, "Matrix metalloproteinase inhibition after myocardial infarction: a new approach to prevent heart failure?" Circulation Research, vol. 89, no. 3, pp. 201-210, 2001.

[15] C. M. Dollery, J. R. McEwan, and A. M. Henney, "Matrix metalloproteinases and cardiovascular disease," Circulation Research, vol. 77, no. 5, pp. 863-868, 1995.

[16] F. G. Spinale, M. L. Coker, B. R. Bond, and J. L. Zellner, "Myocardial matrix degradation and metalloproteinase activation in the failing heart: a potential therapeutic target," Cardiovascular Research, vol. 46, no. 2, pp. 225-238, 2000.
[17] H. Birkedal-Hansen, "Proteolytic remodeling of extracellular matrix," Current Opinion in Cell Biology, vol. 7, no. 5, pp. 728735, 1995.

[18] J. Cao, H. Sato, T. Takino, and M. Seiki, “The C-terminal region of membrane type matrix metalloproteinase is a functional transmembrane domain required for pro-gelatinase A activation," The Journal of Biological Chemistry, vol. 270, no. 2, pp. 801-805, 1995.

[19] G. Murphy and J. Gavrilovic, "Proteolysis and cell migration: creating a path?" Current Opinion in Cell Biology, vol. 11, no. 5, pp. 614-621, 1999.

[20] C. M. O'Connor and M. X. FitzGerald, "Matrix metalloproteases and lung disease," Thorax, vol. 49, no. 6, pp. 602-609, 1994.

[21] U. K. Saarialho-Kere, E. S. Chang, H. G. Welgus, and W. C. Parks, "Distinct localization of collagenase and tissue inhibitor of metalloproteinases expression in wound healing associated with ulcerative pyogenic granuloma," Journal of Clinical Investigation, vol. 90, no. 5, pp. 1952-1957, 1992.

[22] H. Sato, T. Takino, Y. Okada et al., "A matrix metalloproteinase expressed on the surface of invasive tumour cells," Nature, vol. 370, no. 6484, pp. 61-65, 1994.

[23] F. G. Spinale, M. L. Coker, C. V. Thomas, J. D. Walker, R. Mukherjee, and L. Hebbar, "Time-dependent changes in matrix metalloproteinase activity and expression during the progression of congestive heart failure: relation to ventricular and myocyte function," Circulation Research, vol. 82, no. 4, pp. 482-495, 1998.

[24] A. Y. Strongin, I. Collier, G. Bannikov, B. L. Marmer, G. A. Grant, and G. I. Goldberg, "Mechanism of cell surface activation of $72-\mathrm{kDa}$ type IV collagenase. Isolation of the activated form of the membrane metalloprotease," The Journal of Biological Chemistry, vol. 270, no. 10, pp. 5331-5338, 1995.

[25] Q. Yu and I. Stamenkovic, "Cell surface-localized matrix metalloproteinase- 9 proteolytically activates TGF- $\beta$ and promotes tumor invasion and angiogenesis," Genes and Development, vol. 14, no. 2, pp. 163-176, 2000.

[26] A. Okada, J.-P. Belloco, N. Rouyer et al., "Membrane-type matrix metalloproteinase (MT-MMP) gene is expressed in stromal cells of human colon, breast, and head and neck carcinomas," Proceedings of the National Academy of Sciences of the United States of America, vol. 92, no. 7, pp. 2730-2734, 1995.

[27] F. Grams, R. Huber, L. F. Kress, L. Moroder, and W. Bode, "Activation of snake venom metalloproteinases by a cysteine switch-like mechanism," FEBS Letters, vol. 335, no. 1, pp. 76-80, 1993.

[28] A. D. Kandasamy, A. K. Chow, M. A. M. Ali, and R. Schulz, "Matrix metalloproteinase-2 and myocardial oxidative stress injury: beyond the matrix," Cardiovascular Research, vol. 85, no. 3, pp. 413-423, 2010.

[29] H.-J. Ra and W. C. Parks, "Control of matrix metalloproteinase catalytic activity," Matrix Biology, vol. 26, no. 8, pp. 587-596, 2007.

[30] W. G. Stetler-Stevenson, “The tumor microenvironment: regulation by MMP-independent effects of tissue inhibitor of metalloproteinases-2," Cancer and Metastasis Reviews, vol. 27, no. 1, pp. 57-66, 2008.

[31] I. Tency, H. Verstraelen, I. Kroes et al., "Imbalances between matrix metalloproteinases (MMPs) and tissue inhibitor of metalloproteinases (TIMPs) in maternal serum during preterm labor," PLoS ONE, vol. 7, Article ID e49042, 2012. 
[32] E. R. Frears, Z. Zhang, D. R. Blake, J. P. O'Connell, and P. G. Winyard, "Inactivation of tissue inhibitor of metalloproteinase1 by peroxynitrite," FEBS Letters, vol. 381, no. 1-2, pp. 21-24, 1996.

[33] L. M. Golub, H. M. Lee, M. E. Ryan, W. V. Giannobile, J. Payne, and T. Sorsa, "Tetracyclines inhibit connective tissue breakdown by multiple non-antimicrobial mechanisms," Advances in Dental Research, vol. 12, no. 2, pp. 12-26, 1998.

[34] B. Winding, R. NicAmhlaoibh, H. Misander et al., "Synthetic matrix metalloproteinase inhibitors inhibit growth of established breast cancer osteolytic lesions and prolong survival in mice," Clinical Cancer Research, vol. 8, no. 6, pp. 1932-1939, 2002.

[35] S. A. Watson and G. Tierney, "Matrix metalloproteinase inhibitors: a review," BioDrugs, vol. 9, no. 4, pp. 325-335, 1998.

[36] K. Maskos and W. Bode, "Structural basis of matrix metalloproteinases and tissue inhibitors of metalloproteinases," Applied Biochemistry and Biotechnology B, vol. 25, no. 3, pp. 241-266, 2003.

[37] J. Hu, P. E. van den Steen, Q.-X. A. Sang, and G. Opdenakker, "Matrix metalloproteinase inhibitors as therapy for inflammatory and vascular diseases," Nature Reviews Drug Discovery, vol. 6, no. 6, pp. 480-498, 2007.

[38] M. M. Castro and J. E. Tanus-Santos, "Inhibition of matrix metalloproteinases (MMPs) as a potential strategy to ameliorate hypertension-induced cardiovascular alterations," Current Drug Targets, vol. 14, pp. 335-343, 2013.

[39] S. Brown, S. O. Meroueh, R. Fridman, and S. Mobashery, "Quest for selectivity in inhibition of matrix metalloproteinases," Current Topics in Medicinal Chemistry, vol. 4, no. 12, pp. 1227-1238, 2004.

[40] H. Matter and W. Schwab, "Affinity and selectivity of matrix metalloproteinase inhibitors: a chemometrical study from the perspective of ligands and proteins," Journal of Medicinal Chemistry, vol. 42, no. 22, pp. 4506-4523, 1999.

[41] S. Higashi, T. Hirose, T. Takeuchi, and K. Miyazaki, "Molecular design of a highly selective and strong protein inhibitor against matrix metalloproteinase-2 (MMP-2)," The Journal of Biological Chemistry, vol. 288, pp. 9066-9076, 2013.

[42] Y. Xiong and K. L. Guan, "Mechanistic insights into the regulation of metabolic enzymes by acetylation," The Journal of Cell Biology, vol. 198, pp. 155-164, 2012.

[43] E. Appella and C. W. Anderson, "Post-translational modifications and activation of p53 by genotoxic stresses," European Journal of Biochemistry, vol. 268, no. 10, pp. 2764-2772, 2001.

[44] D. T. Hess and J. S. Stamler, "Regulation by S-nitrosylation of protein post-translational modification," The Journal of Biological Chemistry, vol. 287, no. 7, pp. 4411-4418, 2012.

[45] A. Boneh, "Regulation of mitochondrial oxidative phosphorylation by second messenger-mediated signal transduction mechanisms," Cellular and Molecular Life Sciences, vol. 63, no. 11, pp. 1236-1248, 2006.

[46] I. V. Schemarova, "The role of tyrosine phosphorylation in regulation of signal transduction pathways in unicellualr eukaryotes," Current Issues in Molecular Biology, vol. 8, no. 1, pp. 27-50, 2006.

[47] G. Pfitzer, "Invited review: regulation of myosin phosphorylation in smooth muscle," Journal of Applied Physiology, vol. 91, no. 1, pp. 497-503, 2001.

[48] T. Okamoto, T. Akaike, T. Nagano et al., "Activation of human neutrophil procollagenase by nitrogen dioxide and peroxynitrite: a novel mechanism for procollagenase activation involving nitric oxide," Archives of Biochemistry and Biophysics, vol. 342, no. 2, pp. 261-274, 1997.

[49] T. Okamoto, T. Akaike, T. Sawa, Y. Miyamoto, A. van der Vliet, and H. Maeda, "Activation of matrix metalloproteinases by peroxynitrite-induced protein S-glutathiolation via disulfide Soxide formation," The Journal of Biological Chemistry, vol. 276, no. 31, pp. 29596-29602, 2001.

[50] S. Viappiani, A. C. Nicolescu, A. Holt et al., "Activation and modulation of $72 \mathrm{kDa}$ matrix metalloproteinase- 2 by peroxynitrite and glutathione," Biochemical Pharmacology, vol. 77, no. 5, pp. 826-834, 2009.

[51] S. Viappiani, A. C. Nicolescu, A. Holt et al., "Activation and modulation of $72 \mathrm{kDa}$ matrix metalloproteinase- 2 by peroxynitrite and glutathione," Biochemical Pharmacology, vol. 77, no. 5, pp. 826-834, 2009.

[52] S. Donnini, M. Monti, R. Roncone et al., "Peroxynitrite inactivates human-tissue inhibitor of metalloproteinase-4," FEBS Letters, vol. 582, no. 7, pp. 1135-1140, 2008.

[53] M. Sariahmetoglu, B. D. Crawford, H. Leon et al., "Regulation of matrix metalloproteinase-2 (MMP-2) activity by phosphorylation," FASEB Journal, vol. 21, no. 10, pp. 2486-2495, 2007.

[54] A. L. Jacob-Ferreira, M. Y. Kondo, P. K. Baral et al., "Phosphorylation status of $72 \mathrm{kDa}$ MMP-2 determines its structure and activity in response to peroxynitrite," PLoS ONE, vol. 8, Article ID e71794, 2013.

[55] A. L. Jacob-Ferreira and R. Schulz, "Activation of intracellular matrix metalloproteinase- 2 by reactive oxygen-nitrogen species: consequences and therapeutic strategies in the heart," Archives of Biochemistry and Biophysics, vol. 540, no. 1-2, pp. 8293, 2013.

[56] M. Sariahmetoglu, M. Skrzypiec-Spring, N. Youssef et al., "Phosphorylation status of matrix metalloproteinase 2 in myocardial ischaemia-reperfusion injury," Heart, vol. 98, no. 8, pp. 656-662, 2012.

[57] P.-Y. Cheung, G. Sawicki, E. Salas, P. C. Etches, R. Schulz, and M. W. Radomski, "The mechanisms of platelet dysfunction during extracorporeal membrane oxygenation in critically ill neonates," Critical Care Medicine, vol. 28, no. 7, pp. 2584-2590, 2000.

[58] G. Sawicki, E. Salas, J. Murat, H. Miszta-Lane, and M. W. Radomski, "Release of gelatinase A during platelet activation mediates aggregation," Nature, vol. 386, no. 6625, pp. 616-619, 1997.

[59] G. Sawicki, E. J. Sanders, E. Salas, M. Wozniak, J. Rodrigo, and M. W. Radomski, "Localization and translocation of MMP2 during aggregation of human platelets," Thrombosis and Haemostasis, vol. 80, no. 5, pp. 836-839, 1998.

[60] C. Fernandez-Patron, M. A. Martinez-Cuesta, E. Salas et al., "Differential regulation of platelet aggregation by matrix metalloproteinases-9 and -2," Thrombosis and Haemostasis, vol. 82, no. 6, pp. 1730-1735, 1999.

[61] C. Fernandez-Patron, M. W. Radomski, and S. T. Davidge, "Vascular matrix metalloproteinase-2 cleaves big endothelin-1 yielding a novel vasoconstrictor," Circulation Research, vol. 85, no. 10, pp. 906-911, 1999.

[62] C. Fernandez-Patron, K. G. Stewart, Y. Zhang, E. Koivunen, M. W. Radomski, and S. T. Davidge, "Vascular matrix metalloproteinase-2-dependent cleavage of calcitonin generelated peptide promotes vasoconstriction," Circulation Research, vol. 87, no. 8, pp. 670-676, 2000.

[63] G. A. McQuibban, J.-H. Gong, E. M. Tam, C. A. G. McCulloch, I. Clark-Lewis, and C. M. Overall, "Inflammation dampened by 
gelatinase a cleavage of monocyte chemoattractant protein-3," Science, vol. 289, no. 5482, pp. 1202-1206, 2000.

[64] K. Zhang, G. A. McQuibban, C. Silva et al., "HIV-induced metalloproteinase processing of the chemokine stromal cell derived factor-1 causes neurodegeneration," Nature Neuroscience, vol. 6, no. 10, pp. 1064-1071, 2003.

[65] P. Rouet-Benzineb, J.-M. Buhler, P. Dreyfus et al., "Altered balance between matrix gelatinases (MMP-2 and MMP-9) and their tissue inhibitors in human dilated cardiomyopathy: potential role of MMP-9 in myosin-heavy chain degradation," European Journal of Heart Failure, vol. 1, no. 4, pp. 337-352, 1999.

[66] T. Yamazaki, J.-D. Lee, H. Shimizu, H. Uzui, and T. Ueda, "Circulating matrix metalloproteinase-2 is elevated in patients with congestive heart failure," European Journal of Heart Failure, vol. 6, no. 1, pp. 41-45, 2004.

[67] W. Wang, C. J. Schulze, W. L. Suarez-Pinzon, J. R. B. Dyck, G. Sawicki, and R. Schulz, "Intracellular action of matrix metalloproteinase-2 accounts for acute myocardial ischemia and reperfusion injury," Circulation, vol. 106, no. 12, pp. 15431549, 2002.

[68] G. Sawicki, H. Leon, J. Sawicka et al., "Degradation of myosin light chain in isolated rat hearts subjected to ischemiareperfusion injury: a new intracellular target for matrix metalloproteinase-2," Circulation, vol. 112, no. 4, pp. 544-552, 2005.

[69] J. A. Kwan, C. J. Schulze, W. Wang et al., "Matrix metalloproteinase-2 (MMP-2) is present in the nucleus of cardiac myocytes and is capable of cleaving poly (ADP-ribose) polymerase (PARP) in vitro," FASEB Journal, vol. 18, no. 6, pp. 690-692, 2004.

[70] B. Menon, J. N. Johnson, R. S. Ross, M. Singh, and K. Singh, "Glycogen synthase kinase- $3 \beta$ plays a pro-apoptotic role in $\beta$ adrenergic receptor-stimulated apoptosis in adult rat ventricular myocytes: role of $\beta 1$ integrins," Journal of Molecular and Cellular Cardiology, vol. 42, no. 3, pp. 653-661, 2007.

[71] H.-Z. Zhou, X. Ma, M. O. Gray et al., "Transgenic MMP-2 expression induces latent cardiac mitochondrial dysfunction," Biochemical and Biophysical Research Communications, vol. 358, no. 1, pp. 189-195, 2007.

[72] K. Si-Tayeb, A. Monvoisin, C. Mazzocco et al., "Matrix metalloproteinase 3 is present in the cell nucleus and is involved in apoptosis," American Journal of Pathology, vol. 169, no. 4, pp. 1390-1401, 2006.

[73] G. A. Limb, K. Matter, G. Murphy et al., "Matrix metalloproteinase-1 associates with intracellular organelles and confers resistance to lamin A/C Degradation during apoptosis," American Journal of Pathology, vol. 166, no. 5, pp. 1555-1563, 2005.

[74] K. S. Moshal, S. M. Tipparaju, T. P. Vacek et al., "Mitochondrial matrix metalloproteinase activation decreases myocyte contractility in hyperhomocysteinemia," American Journal of Physiology: Heart and Circulatory Physiology, vol. 295, no. 2, pp. H890-H897, 2008.

[75] A. Doucet and C. M. Overall, "Protease proteomics: revealing protease in vivo functions using systems biology approaches," Molecular Aspects of Medicine, vol. 29, no. 5, pp. 339-358, 2009.

[76] L. J. McCawley and L. M. Matrisian, "Matrix metalloproteinases: they're not just for matrix anymore!" Current Opinion in Cell Biology, vol. 13, no. 5, pp. 534-540, 2001.

[77] D. M. Hockenbery, "MMPs in unusual places," American Journal of Pathology, vol. 169, no. 4, pp. 1101-1103, 2006.
[78] D. H. Lovett, R. Mahimkar, R. L. Raffai et al., "N-terminal truncated intracellular matrix metalloproteinase- 2 induces cardiomyocyte hypertrophy, inflammation and systolic heart failure," PLoS ONE, vol. 8, Article ID e68154, 2013.

[79] F. G. Spinale and N. M. Wilbur, "Matrix metalloproteinase therapy in heart failure," Current Treatment Options in Cardiovascular Medicine, vol. 11, no. 4, pp. 339-346, 2009.

[80] Z. S. Galis and J. J. Khatri, "Matrix metalloproteinases in vascular remodeling and atherogenesis: the good, the bad, and the ugly," Circulation Research, vol. 90, no. 3, pp. 251-262, 2002.

[81] P.-Y. Cheung, G. Sawicki, M. Wozniak, W. Wang, M. W. Radomski, and R. Schulz, "Matrix metalloproteinase-2 contributes to ischemia-reperfusion injury in the heart," Circulation, vol. 101, no. 15, pp. 1833-1839, 2000.

[82] C. J. Schulze, W. Wang, W. L. Suarez-Pinzon, J. Sawicka, G. Sawicki, and R. Schulz, "Imbalance between tissue inhibitor of metalloproteinase-4 and matrix metalloproteinases during acute myocardial ischemia-reperfusion injury," Circulation, vol. 107, no. 19, pp. 2487-2492, 2003.

[83] J. Fert-Bober, H. Leon, J. Sawicka et al., "Inhibiting matrix metalloproteinase- 2 reduces protein release into coronary effluent from isolated rat hearts during ischemia-reperfusion," Basic Research in Cardiology, vol. 103, no. 5, pp. 431-443, 2008.

[84] A. Doroszko, D. Polewicz, V. J. J. Cadete et al., "Neonatal asphyxia induces the nitration of cardiac myosin light chain 2 that is associated with cardiac systolic dysfunction," Shock, vol. 34, no. 6, pp. 592-600, 2010.

[85] M. A. M. Ali, W. J. Cho, B. Hudson, Z. Kassiri, H. Granzier, and R. Schulz, "Titin is a target of matrix metalloproteinase2: implications in myocardial ischemia/reperfusion injury," Circulation, vol. 122, no. 20, pp. 2039-2047, 2010.

[86] R. Schulz, "Intracellular targets of matrix metalloproteinase-2 in cardiac disease: rationale and therapeutic approaches," Annual Review of Pharmacology and Toxicology, vol. 47, pp. 211-242, 2007.

[87] F. G. Spinale, "Myocardial matrix remodeling and the matrix metalloproteinases: influence on cardiac form and function," Physiological Reviews, vol. 87, no. 4, pp. 1285-1342, 2007.

[88] S. Bharath and J. K. Andersen, "Glutathione depletion in a midbrain-derived immortalized dopaminergic cell line results in limited tyrosine nitration of mitochondrial complex I subunits: implications for Parkinson's disease," Antioxidants and Redox Signaling, vol. 7, no. 7-8, pp. 900-910, 2005.

[89] D. Paris, T. A. Parker, T. Town et al., "Role of peroxynitrite in the vasoactive and cytotoxic effects of alzheimer's $\beta$-amyloid140 peptide," Experimental Neurology, vol. 152, no. 1, pp. 116-122, 1998.

[90] F. Schliess, N. Foster, B. Görg, R. Reinehr, and D. Häussinger, "Hypoosmotic swelling increases protein tyrosine nitration in cultured rat astrocytes," Glia, vol. 47, no. 1, pp. 21-29, 2004.

[91] V. Srinivasan, S. R. Pandi-Perumal, G. J. M. Maestroni, A. I. Esquifino, R. Hardeland, and D. P. Cardinali, "Role of melatonin in neurodegenerative diseases," Neurotoxicity Research, vol. 7, no. 4, pp. 293-318, 2005.

[92] T. Csont and P. Ferdinandy, "Cardioprotective effects of glyceryl trinitrate: beyond vascular nitrate tolerance," Pharmacology and Therapeutics, vol. 105, no. 1, pp. 57-68, 2005.

[93] A. Dominguez-Rodriguez, P. Abreu-Gonzalez, A. de la Rosa, M. Vargas, J. Ferrer, and M. Garcia, "Role of endogenous interleukin-10 production and lipid peroxidation in patients with acute myocardial infarction treated with primary percutaneous transluminal coronary angioplasty interleukin-10 and 
primary angioplasty," International Journal of Cardiology, vol. 99, no. 1, pp. 77-81, 2005.

[94] M. Tecder-Ünal and Ý. Kanzýk, "Peroxynitrite in reperfusion arrhythmias and its whole blood chemiluminescence results," Pharmacological Research, vol. 49, no. 1, pp. 7-16, 2004.

[95] C. D. Mcdermott, S. M. Gavita, H. Shennib, and A. Giaid, "Immunohistochemical localization of nitric oxide synthase and the oxidant peroxynitrite in lung transplantation recipients with obliterative bronchiolitis," Transplantation, vol. 64, no. 2 , pp. 270-274, 1997.

[96] D. Saleh, P. Ernst, S. Lim, P. J. Barnes, and A. Giaid, "Increased formation of the potent oxidant peroxynitrite in the airways of asthmatic patients is associated with induction of nitric oxide synthase: effect of inhaled glucocorticoid," FASEB Journal, vol. 12, no. 11, pp. 929-937, 1998.

[97] Y. Lu, X. Wang, and A. I. Cederbaum, "Lipopolysaccharideinduced liver injury in rats treated with the CYP2E1 inducer pyrazole," American Journal of Physiology: Gastrointestinal and Liver Physiology, vol. 289, no. 2, pp. G308-G319, 2005.

[98] S. Shiva, J.-Y. Oh, A. L. Landar et al., "Nitroxia: the pathological consequence of dysfunction in the nitric oxide-cytochrome $\mathrm{c}$ oxidase signaling pathway," Free Radical Biology and Medicine, vol. 38, no. 3, pp. 297-306, 2005.

[99] C.-L. M. Cooke and S. T. Davidge, "Peroxynitrite increases iNOS through NF- $\kappa \mathrm{B}$ and decreases prostacyclin synthase in endothelial cells," American Journal of Physiology: Cell Physiology, vol. 282, no. 2, pp. C395-C402, 2002.

[100] A. M. Roggensack, Y. Zhang, and S. T. Davidge, "Evidence for peroxynitrite formation in the vasculature of women with preeclampsia," Hypertension, vol. 33, no. 1, pp. 83-89, 1999.

[101] L. Boscá, M. Zeini, P. G. Través, and S. Hortelano, "Nitric oxide and cell viability in inflammatory cells: a role for NO in macrophage function and fate," Toxicology, vol. 208, no. 2, pp. 249-258, 2005.

[102] Y. Hayashi, Y. Sawa, M. Nishimura et al., "Peroxynitrite, a product between nitric oxide and superoxide anion, plays a cytotoxic role in the development of post-bypass systemic inflammatory response," European Journal of Cardio-thoracic Surgery, vol. 26, no. 2, pp. 276-280, 2004.

[103] S. Levrand, B. Pesse, F. Feihl et al., "Peroxynitrite is a potent inhibitor of NF- $\kappa$ B activation triggered by inflammatory stimuli in cardiac and endothelial cell lines," The Journal of Biological Chemistry, vol. 280, no. 41, pp. 34878-34887, 2005.

[104] H. Ohmori and N. Kanayama, "Immunogenicity of an inflammation-associated product, tyrosine nitrated selfproteins," Autoimmunity Reviews, vol. 4, no. 4, pp. 224-229, 2005.

[105] J. A. Byrne, D. J. Grieve, A. C. Cave, and A. M. Shah, "Oxidative stress and heart failure," Archives des Maladies du Coeur et des Vaisseaux, vol. 96, no. 3, pp. 214-221, 2003.

[106] J. S. Beckman and W. H. Koppenol, "Nitric oxide, superoxide, and peroxynitrite: the good, the bad, and the ugly," American Journal of Physiology: Cell Physiology, vol. 271, no. 5, pp. C1424C1437, 1996.

[107] E. Murphy and C. Steenbergen, "Mechanisms underlying acute protection from cardiac ischemia-reperfusion injury," Physiological Reviews, vol. 88, no. 2, pp. 581-609, 2008.

[108] D. Polewicz, V. J. J. Cadete, A. Doroszko et al., "Ischemia induced peroxynitrite dependent modifications of cardiomyocyte MLC1 increases its degradation by MMP-2 leading to contractile dysfunction," Journal of Cellular and Molecular Medicine, vol. 15, no. 5, pp. 1136-1147, 2011.
[109] P. Ferdinandy and R. Schulz, "Nitric oxide, superoxide, and peroxynitrite in myocardial ischaemia-reperfusion injury and preconditioning," British Journal of Pharmacology, vol. 138, no. 4, pp. 532-543, 2003.

[110] R. Schulz and C. R. Triggle, "Role of NO in vascular smooth muscle and cardiac muscle function," Trends in Pharmacological Sciences, vol. 15, no. 7, pp. 255-259, 1994.

[111] J.-L. Balligand and P. J. Cannon, "Nitric oxide synthases and cardiac muscle: autocrine and paracrine influences," Arteriosclerosis, Thrombosis, and Vascular Biology, vol. 17, no. 10, pp. 18461858, 1997.

[112] L. Xi and R. C. Kukreja, "Pivotal role of nitric oxide in delayed pharmacological preconditioning against myocardial infarction," Toxicology, vol. 155, no. 1-3, pp. 37-44, 2000.

[113] T. O. Nossuli, R. Hayward, D. Jensen, R. Scalia, and A. M. Lefer, "Mechanisms of cardioprotection by peroxynitrite in myocardial ischemia and reperfusion injury," American Journal of Physiology: Heart and Circulatory Physiology, vol. 275, no. 2, pp. H509-H519, 1998.

[114] X.-L. Tang, H. Takano, A. Rizvi et al., "Oxidant species trigger late preconditioning against myocardial stunning in conscious rabbits," American Journal of Physiology: Heart and Circulatory Physiology, vol. 282, no. 1, pp. H281-H291, 2002.

[115] J. Li, N. Loukili, N. Rosenblatt-Velin et al., "Peroxynitrite is a key mediator of the cardioprotection afforded by ischemic postconditioning in vivo," PLoS ONE, vol. 8, Article ID e70331, 2013.

[116] R. Schulz, E. Nava, and S. Moncada, "Induction and potential biological relevance of a $\mathrm{Ca}^{2+}$-independent nitric oxide synthase in the myocardium," British Journal of Pharmacology, vol. 105, no. 3, pp. 575-580, 1992.

[117] R. Schulz, K. L. Dodge, G. D. Lopaschuk, and A. S. Clanachan, "Peroxynitrite impairs cardiac contractile function by decreasing cardiac efficiency," American Journal of Physiology: Heart and Circulatory Physiology, vol. 272, no. 3, pp. H1212-H1219, 1997.

[118] D. Panas, F. H. Khadour, C. Szabó, and R. Schulz, "Proinflammatory cytokines depress cardiac efficiency by a nitric oxidedependent mechanism," American Journal of Physiology: Heart and Circulatory Physiology, vol. 275, no. 3, pp. H1016-H1023, 1998.

[119] R. Schulz, D. L. Panas, R. Catena, S. Moncada, P. M. Olley, and G. D. Lopaschuk, "The role of nitric oxide in cardiac depression induced by interleukin- $1 \beta$ and tumour necrosis factor- $\alpha$," British Journal of Pharmacology, vol. 114, no. 1, pp. 2734, 1995.

[120] W. Yasmin, K. D. Strynadka, and R. Schulz, "Generation of peroxynitrite contributes to ischemia-reperfusion injury in isolated rat hearts," Cardiovascular Research, vol. 33, no. 2, pp. 422-432, 1997.

[121] Z. Gu, M. Kaul, B. Yan et al., "S-nitrosylation of matrix metalloproteinases: signaling pathway to neuronal cell death," Science, vol. 297, no. 5584, pp. 1186-1190, 2002.

[122] A. Kulisz, N. Chen, N. S. Chandel, Z. Shao, and P. T. Schumacker, "Mitochondrial ROS initiate phosphorylation of p38 MAP kinase during hypoxia in cardiomyocytes," American Journal of Physiology: Lung Cellular and Molecular Physiology, vol. 282, no. 6, pp. L1324-L1329, 2002.

[123] Y. Son, Y. K. Cheong, N. H. Kim, H. T. Chung, D. G. Kang, and H. O. Pae, "Mitogen-activated protein kinases and reactive oxygen species: how can ROS activate MAPK pathways?" 
Journal of Signal Transduction, vol. 2011, Article ID 792639, 6 pages, 2011.

[124] F. Esposito, G. Chirico, N. M. Gesualdi et al., "Protein kinase B activation by reactive oxygen species is independent of tyrosine kinase receptor phosphorylation and requires Src activity," The Journal of Biological Chemistry, vol. 278, no. 23, pp. 2082820834, 2003.

[125] E. Giannoni, F. Buricchi, G. Raugei, G. Ramponi, and P. Chiarugi, "Intracellular reactive oxygen species activate Src tyrosine kinase during cell adhesion and anchorage-dependent cell growth," Molecular and Cellular Biology, vol. 25, no. 15, pp. 6391-6403, 2005.

[126] Z. Balafanova, R. Bolli, J. Zhang et al., "Nitric oxide (NO) induces nitration of protein kinase $\mathrm{C} \varepsilon(\mathrm{PKC} \varepsilon)$, facilitating $\mathrm{PKC} \varepsilon$ translocation via enhanced PKC $\varepsilon$-RACK2 interactions. A novel mechanism of no-triggered activation of PKCe," The Journal of Biological Chemistry, vol. 277, no. 17, pp. 15021-15027, 2002.

[127] A. Doroszko, D. Polewicz, J. Sawicka, J. S. Richardson, G. Sawicki, and P.-Y. Cheung, "Cardiac dysfunction in an animal model of neonatal asphyxia is associated with increased degradation of MLC1 by MMP-2," Basic Research in Cardiology, vol. 104, no. 6, pp. 669-679, 2009.

[128] V. J. Cadete, J. Sawicka, J. S. Jaswal et al., "Ischemia/reperfusioninduced myosin light chain 1 phosphorylation increases its degradation by matrix metalloproteinase 2," FEBS Journal, vol. 279, pp. 2444-2454, 2012.

[129] K. Arrell, I. Neverova, H. Fraser, E. Marbán, and J. E. van Eyk, "Proteomic analysis of pharmacologically preconditioned cardiomyocytes reveals novel phosphorylation of myosin light chain 1," Circulation Research, vol. 89, no. 6, pp. 480-487, 2001.

[130] I. Morano, J. Rosch, A. Arner, and J.-C. Ruegg, "Phosphorylation and thiophosphorylation by myosin light chain kinase: different effects of mechanical properties of chemically skinned ventricular fibers from the pig," Journal of Molecular and Cellular Cardiology, vol. 22, no. 7, pp. 805-813, 1990.

[131] A. Moretti, H.-J. Weig, T. Ott et al., "Essential myosin light chain as a target for caspase-3 in failing myocardium," Proceedings of the National Academy of Sciences of the United States of America, vol. 99, no. 18, pp. 11860-11865, 2002.

[132] G. Sawicki and B. I. Jugdutt, "Valsartan reverses posttranslational modifications of the $\delta$-subunit of ATP synthase during in vivo canine reperfused myocardial infarction," Proteomics, vol. 7, no. 12, pp. 2100-2110, 2007.

[133] M. C. Pustovrh, A. Jawerbaum, E. Capobianco et al., "Oxidative stress promotes the increase of matrix metalloproteinases- 2 and -9 activities in the feto-placental unit of diabetic rats," Free Radical Research, vol. 39, no. 12, pp. 1285-1293, 2005.

[134] K. Kameda, T. Matsunaga, N. Abe et al., "Correlation of oxidative stress with activity of matrix metalloproteinase in patients with coronary artery disease. Possible role for left ventricular remodelling," European Heart Journal, vol. 24, no. 24, pp. 2180-2185, 2003.

[135] Y. Yang, E. Candelario-Jalil, J. F. Thompson et al., "Increased intranuclear matrix metalloproteinase activity in neurons interferes with oxidative DNA repair in focal cerebral ischemia," Journal of Neurochemistry, vol. 112, no. 1, pp. 134-149, 2010.

[136] C. S. Alge-Priglinger, T. Kreutzer, K. Obholzer et al., "Oxidative stress-mediated induction of MMP-1 and MMP-3 in human RPE cells," Investigative Ophthalmology and Visual Science, vol. 50, no. 11, pp. 5495-5503, 2009.

[137] J. Fert-Bober, R. S. Basran, J. Sawicka, and G. Sawicki, "Effect of duration of ischemia on myocardial proteome in ischemia/reperfusion injury," Proteomics, vol. 8, no. 12, pp. 2543-2555, 2008.

[138] G. Sawicki and B. I. Jugdutt, "Detection of regional changes in protein levels in the in vivo canine model of acute heart failure following ischemia reperfusion injury: functional proteomics studies," Proteomics, vol. 4, no. 7, pp. 2195-2202, 2004.

[139] Z. Ma, G. T. Westermark, Z.-C. Li, U. Engström, and P. Westermark, "Altered immunoreactivity of islet amyloid polypeptide (IAPP) may reflect major modifications of the lapp molecule in amyloidogenesis," Diabetologia, vol. 40, no. 7, pp. 793-801, 1997.

[140] B. Ferger, C. Themann, S. Rose, B. Halliwell, and P. Jenner, "6Hydroxydopamine increases the hydroxylation and nitration of phenylalanine in vivo: implication of peroxynitrite formation," Journal of Neurochemistry, vol. 78, no. 3, pp. 509-514, 2001.

[141] S. Petruzzelli, R. Puntoni, P. Mimotti et al., "Plasma 3nitrotyrosine in cigarette smokers," American Journal of Respiratory and Critical Care Medicine, vol. 156, no. 6, pp. 1902-1907, 1997.

[142] A. van der Vliet, C. A. O’Neill, B. Halliwell, C. E. Cross, and H. Kaur, "Aromatic hydroxylation and nitration of phenylalanine and tyrosine by peroxynitrite: evidence for hydroxyl radical production from peroxynitrite," FEBS Letters, vol. 339, no. 1-2, pp. 89-92, 1994.

[143] W. Wang, G. Sawicki, and R. Schulz, "Peroxynitriteinduced myocardial injury is mediated through matrix metalloproteinase-2," Cardiovascular Research, vol. 53, no. 1, pp. 165-174, 2002.

[144] C. Qun Gao, G. Sawicki, W. L. Suarez-Pinzon et al., "Matrix metalloproteinase-2 mediates cytokine-induced myocardial contractile dysfunction," Cardiovascular Research, vol. 57, no. 2, pp. 426-433, 2003.

[145] E. Haase, D. L. Bigam, Q. B. Nakonechny, D. Rayner, G. Korbutt, and P.-Y. Cheung, "Cardiac function, myocardial glutathione, and matrix metalloproteinase-2 levels in hypoxic newborn pigs reoxygenated by $21 \%, 50 \%$, or $100 \%$ oxygen," Shock, vol. 23 , no. 4, pp. 383-389, 2005.

[146] H. León, I. Baczkó, G. Sawicki, P. E. Light, and R. Schulz, "Inhibition of matrix metalloproteinases prevents peroxynitrite-induced contractile dysfunction in the isolated cardiac myocyte," British Journal of Pharmacology, vol. 153, no. 4, pp. 676-683, 2008.

[147] I. Baczkó, W. R. Giles, and P. Light, "Resting membrane potential regulates $\mathrm{Na}+-\mathrm{Ca}^{2+}$ exchange-mediated $\mathrm{Ca}^{2+}$ overload during hypoxia-reoxygenation in rat ventricular myocytes," Journal of Physiology, vol. 550, no. 3, pp. 889-898, 2003.

[148] I. Baczkó, W. R. Giles, and P. E. Light, "Pharmacological activation of plasma-membrane KATP channels reduces reoxygenation-induced $\mathrm{Ca}^{2+}$ overload in cardiac myocytes via modulation of the diastolic membrane potential," British Journal of Pharmacology, vol. 141, no. 6, pp. 1059-1067, 2004.

[149] I. Baczkó, L. Jones, C. F. McGuigan et al., "Plasma membrane KATP channel-mediated cardioprotection involves posthypoxic reductions in calcium overload and contractile dysfunction: mechanistic insights into cardioplegia," FASEB Journal, vol. 19, no. 8, pp. 980-982, 2005.

[150] B. Meder, C. Laufer, D. Hassel et al., "A single serine in the carboxyl terminus of cardiac essential myosin light chain1 controls cardiomyocyte contractility in vivo," Circulation Research, vol. 104, no. 5, pp. 650-659, 2009.

[151] J. E. van Eyk, F. Powers, W. Law, C. Larue, R. S. Hodges, and R. J. Solaro, "Breakdown and release of myofilament proteins during 
ischemia and ischemia/reperfusion in rat hearts identification of degradation products and effects on the pCa-force relation," Circulation Research, vol. 82, no. 2, pp. 261-271, 1998.

[152] I. Vergroesen, J. E. Kal, J. A. E. Spaan, and H. B. van Wezel, "Myocardial oxygen supply: demand ratio as reference for coronary vasodilatory drug effects in humans," Heart, vol. 78, no. 2, pp. 117-126, 1997.

[153] C. J. Zuurbier, M. van Iterson, and C. Ince, "Functional heterogeneity of oxygen supply-consumption ratio in the heart," Cardiovascular Research, vol. 44, no. 3, pp. 488-497, 1999.

[154] R. A. de Boer, Y. M. Pinto, and D. J. van Veldhuisen, "The imbalance between oxygen demand and supply as a potential mechanism in the pathophysiology of heart failure: the role of microvascular growth and abnormalities," Microcirculation, vol. 10, no. 2, pp. 113-126, 2003.

[155] E. R. Gross and G. J. Gross, "Pharmacologic therapeutics for cardiac reperfusion injury," Expert Opinion on Emerging Drugs, vol. 12, no. 3, pp. 367-388, 2007.

[156] W. Rosamond, K. Flegal, K. Furie et al., "Heart disease and stroke statistics-2008 Update: a report from the American heart association statistics committee and stroke statistics subcommittee," Circulation, vol. 117, no. 4, pp. e25-e46, 2008.

[157] G. Cerisano, P. Buonamici, R. Valenti et al., "Early shortterm doxycycline therapy in patients with acute myocardial infarction and left ventricular dysfunction to prevent the ominous progression to adverse remodelling: the TIPTOP trial," European Heart Journal, 2013.

[158] V. J. Cadete, S. A. Arcand, H. B. Lin, and G. Sawicki, "Synergistic protection of MLC 1 against cardiac ischemia/reperfusioninduced degradation: a novel therapeutic concept for the future," Future Medicinal Chemistry, vol. 5, pp. 389-398, 2013.

[159] G. Sawicki, "Synergistic effect of inhibitors of MMPs and ROSdependent modifications of contractile proteins on protection hearts subjected to oxidative stress," Current Pharmaceutical Design, 2013. 

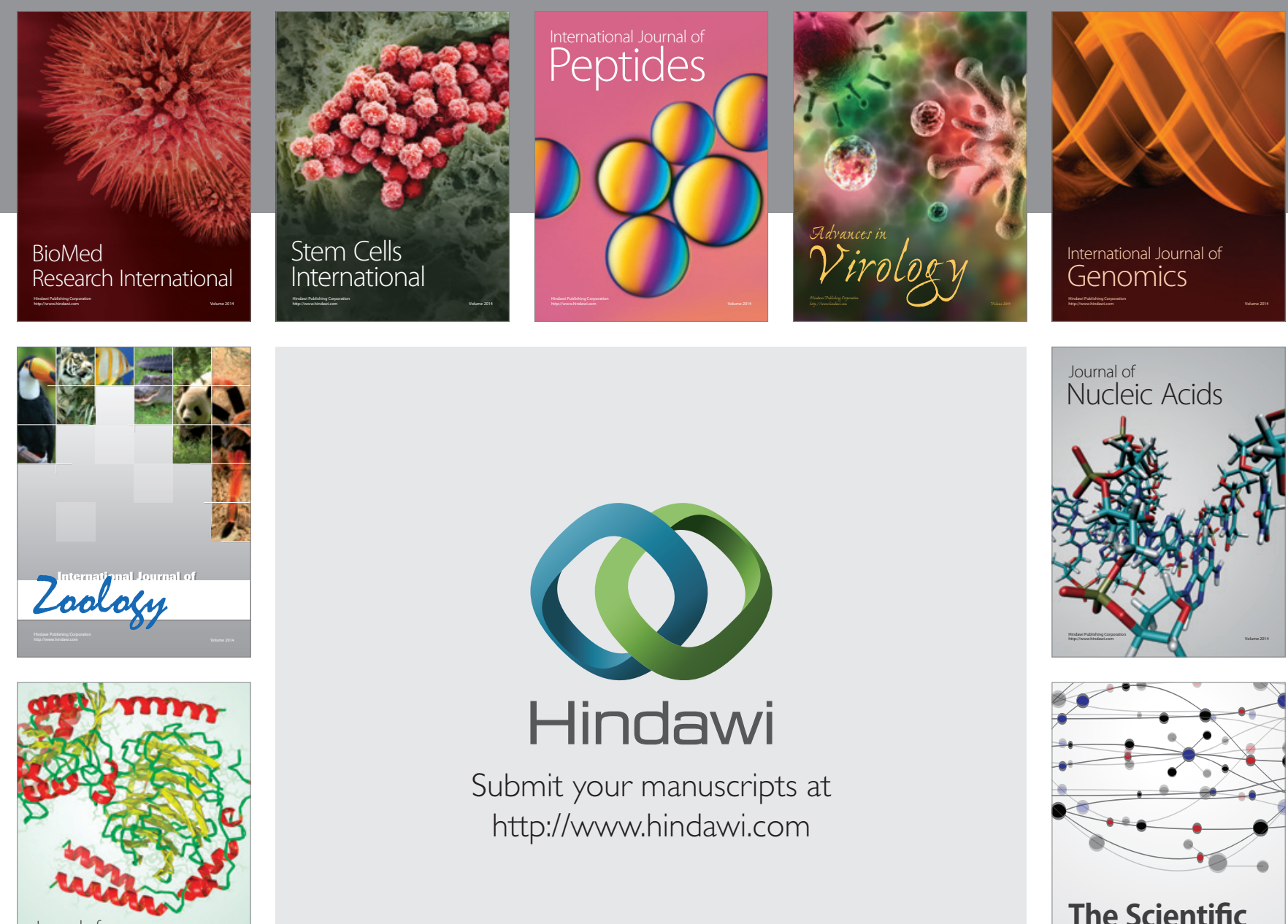

Submit your manuscripts at

http://www.hindawi.com

Journal of
Signal Transduction
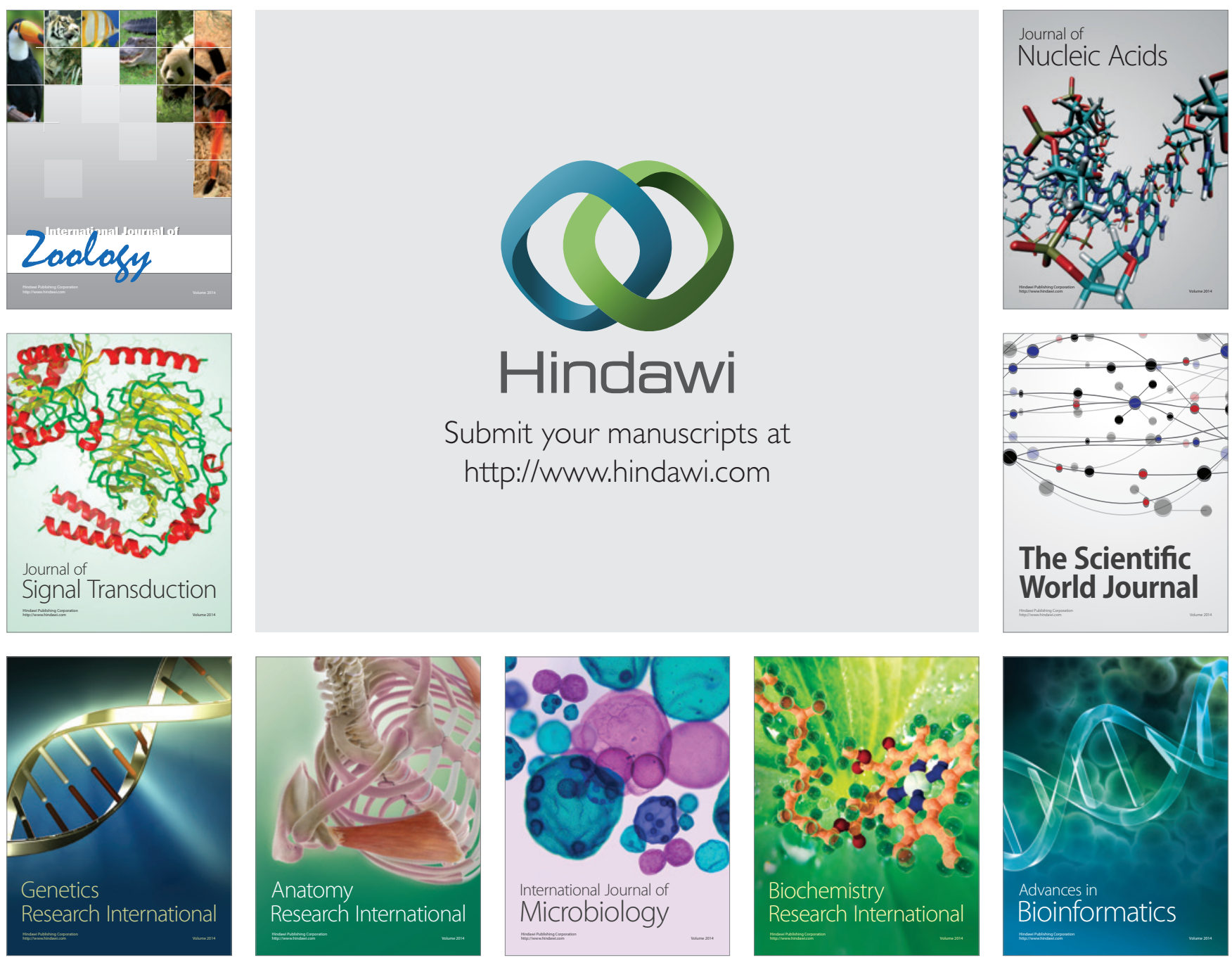

The Scientific World Journal
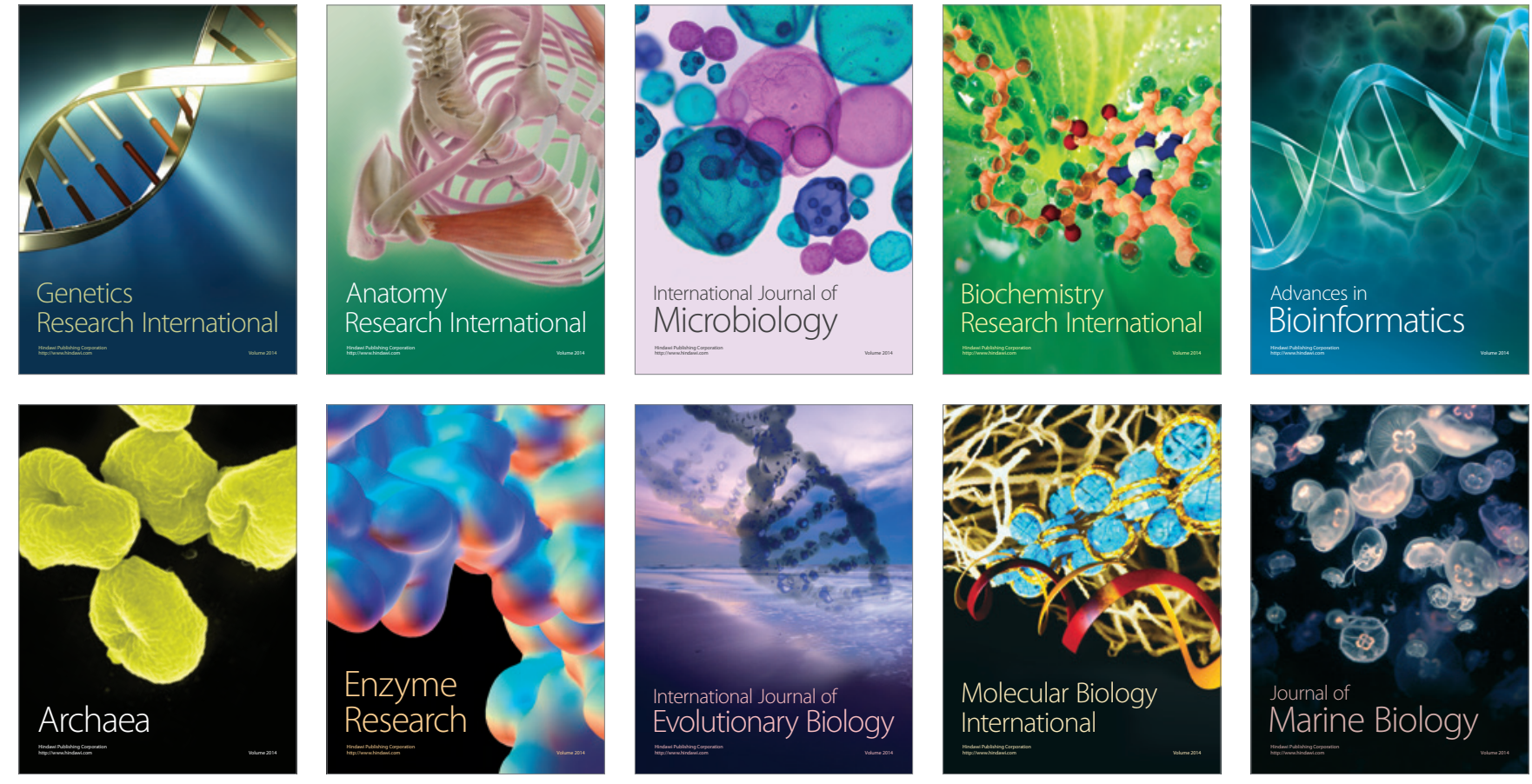